\title{
Report of Five Cases and Literature Review of Psoas Abscess
}

\section{Beș Olgunun Sunumu ve Psoas Apsesinin Literatür Taraması}

\author{
(1) Cafer Özgür Hançerli, (1) Halil Büyükdoğan, (1) Can Eren Ünlü, (1) Anıl Agar, (1) Cemil Ertürk
}

University of Health Sciences Turkey, Kanuni Sultan Süleyman Training and Research Hospital, Clinic of Orthopaedic and Traumatology, İstanbul, Turkey

\begin{abstract}
Objective: To report five psoas abcess cases which we treated and review the management of psoas abscess cases.

Method: Five patients who were diagnosed and treated with psoas abscess in our clinic between 2018 - 2019 were evaluated retrospectively.

Results: Four patients were discharged after an average of 25 days following surgical treatments, and 1 case died on the 24th postoperative day due to sudden cardiac arrest of unknown cause.

Conclusion: Psoas abscesses are rare, we believe that the incidence of these cases is more frequent in recent years due to the improvements in radiological imaging methods and the fact that these tests are used more frequently by clinicians. We think that for the diagnosis of psoas abscess, it is necessary to suspect the diagnosis and keep this rare condition in mind.
\end{abstract}

Keywords: Psoas abscess, percutaneous drainage, open surgery, complication, mortality

\section{ÖZ}

Amaç: Tedavi ettiğimiz beș psoas apsesi vakasını rapor etmek ve psoas apsesi olgularının yönetimini gözden geçirmek.

Yöntem: Kliniğimizde 2018 - 2019 yılları arasında psoas apsesi tanısı konan ve tedavi edilen beș hasta retrospektif olarak incelendi.

Bulgular: Dört hasta gerçekleștirilen cerrahi tedavileri takiben ortalama 25 gün sonra taburcu edilmiş, 1 olgu ise nedeni bilinmeyen ani kardiyak arrest nedeniyle post op 24. gün kaybedilmiștir.

Sonuç: Psoas apsesi nadirdir, radyolojik görüntüleme yöntemlerindeki iyileșmeler ve bu testlerin klinisyenler tarafından daha sık kullanılması nedeniyle bu olguların görülme sıklığının son yıllarda daha sık olduğuna inanıyoruz. Psoas apsesi tanısı için tanıdan șüphelenmek ve bu nadir durumu akılda tutmak gerektiğini düşünüyoruz.

Anahtar kelimeler: Psoas apsesi, perkütan drenaj, açık cerrahi, komplikasyon, mortalite

\section{INTRODUCTION}

Psoas abscess is a rare disease with varying clinical presentation and may be seen in any area from the lumbar region to the inguinal region due to the anatomy and course of the psoas muscle (1). Psoas abcess was identified by Herman Mynter in 1881 for the first time ${ }^{(2)}$. The psoas muscle extending from the legs to the spine is the only muscle that connects the legs and the backbone. The muscles coming out of the T12 vertebrae move towards the lumbar vertebrae and eventually connect to the hip bone (3). It locates nearby organs like kidneys, spine, sigmoid colon, jejunum, appendix, ureters and abdominal aorta. Therefore, infection in these organs may dissolve through the psoas muscle (4).

Psoas abcess can be primary and secondary. Primary psoas abscesses is usually of hematogenic origin and comprises $30 \%$ of all psoas abcesses; secondary psoas abscesses often

Cite as: Hançerli CÖ, Büyükdoğan H, Ünlü CE, Agar A, Ertürk C. Report of Five Cases and Literature Review of Psoas Abscess. İKSSTD 2021;13(3):252-7 
develop from a neighboring pathological process originating from the spine, urinary system or gastro-interstinal system and comprises $70 \%$ of all cases. The diagnosis is often delayed due to the rare occurrence of the disease, the lack of specific clinical findings, and the insidious progression of the infection process ${ }^{(5)}$. Early diagnosis and appropriate treatment can prevent morbidity and mortality. Broad-spectrum antibiotics and drainage percutaneously or by open surgery is the primary treatment of choice for psoas abcess. Especially in secondary psoas abcess mortality rates may increase up to $18.9 \%$ despite these treatment methods ${ }^{(6)}$. Despite the mortal course of the disease, there is no clear consensus between the general surgery, urology and orthopedics as to which department should undertake the treatment.

In the present study, we aimed to evaluate the patients with psoas abscess treated in our clinic retrospectively.

\section{CASE REPORT}

Between january 2018 to October 2019 five patients were diagnosed and treated with psoas abscess in our clinic . Patients whose data could not be reached and who were out of follow-up were excluded from the study There were 7 patients recorded due to the psoas abscess when the medical charts of the patients were reviewed, 2 patients were excluded due to the lack of follow-up. The study group was limited to the five patients. Five patients with psoas abscess were evaluated in a retrospective l-year screening. The mean age of the patients was 33.6 years (range: 13 to 64 years). All cases were male and four patients had left side, one had right side. One patient was young athlete (13 years), 1 patient was student (19 years), 1 patient was homeless (51 years) and 2 patients were workers (21 years and 64 years).
The mean hospital stay was 35.2 (8-87) days and the mean follow-up was 16.8 (13-21) months and the mean time from admission to diagnosis was 17.2 ( 3-30) days.

No urinary tract pathology was detected in any of the patients. As a physical examination finding, hip joint movements were evaluated as painful and limited in all patients. Direct radiography and ultrasonography (USG) were performed in all patients. Computed tomography (CT) and magnetic resonance imaging (MRI) were also performed in case of suspicion or further examination on USG. Only a 13-yearold child was not ordered CT. This was a retrospective clinical study. The present study was approved by the Ethical Committee of our hospital. Demographic characteristics of the patients, clinical presentation, additional disease and predisposing factors, diagnostic methods, time of diagnosis, treatment method, microbiological examination, treatment responses and complications, duration of hospitalization and treatment outcomes were evaluated (Figure 1).

\section{Case 1}

This patient was a young male athlete (13 years). Patient was diagnosed as primary psoas abscess with no additional disease and no other underlying pathology. He was admitted to the pediatric infectious diseases service without surgical intervention and was followed up with systemic empirical antibiotherapy. Patient was consulted for low back, groin and hip pain and high fever. Patient's leukocyte count was 13.54 $\mathrm{k} / \mathrm{mm}^{3}$ and C-reactive protein (CRP) level was $160 \mathrm{mg} / \mathrm{L}$ at admission. The ultrasound and MR images of the harvest revealed collections in the left psoas region (Figure 1). We performed open surgery and abscess drainage. The patient underwent surgery while receiving intensive antibiotic
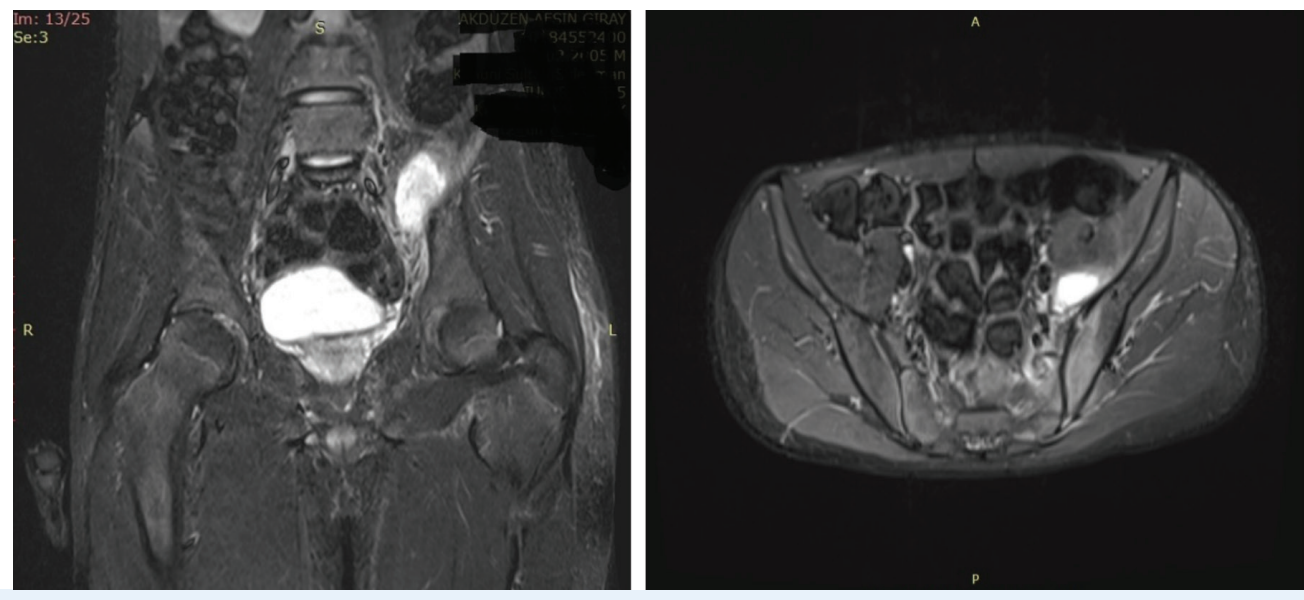

Figure 1. Thirteen years old male left psoas abscess (Case 1) coronal and axial preoperative MR images MR: Magnetic resonance 
therapy, therefore, microorganism growth did not occur in the culture taken during the operation. He was followed with antibiotherapy for an appropriate period after surgery and was discharged without any complications after 34 days of hospitalization. In the postoperative follow-up, the patient's CRP level was $1.04 \mathrm{mg} / \mathrm{L}$ and white blood cell (WBC) level was $7.28 \mathrm{k} / \mathrm{mm}^{3}$.

\section{Case 2}

This patient was a male student (19 years) and presented with low back, groin and hip pain, high fever and difficulty in walking. He had diffuse variable immunodeficiency and lumbar disc hernia and the diagnosis of ankylosing spondylitis for a period of 1 month and during the followup with sulfasalazine treatment. The patient consulted for aggravation of the clinic and worsening of the general condition. He was admitted to anesthesia and reanimation intensive care unit due to general condition disorder and sepsis and systemic antibiotherapy was started. Patient's leukocyte count was $19.43 \mathrm{k} / \mathrm{mm}^{3}$ and CRP level was 279 $\mathrm{mg} / \mathrm{L}$ at admission. He was operated twice during the intensive care stay. Methicillin-sensitive staphylococcus aureus (MSSA) had grown in the culture taken during the operation of the patient. The patient's general condition, clinical findings and laboratory tests improved gradually, and he was ex - as a result of sudden cardiac arrest of unknown cause (total hospital stay 24 days) on the fourth day of admission.

\section{Case 3}

This patients was male worker (21 years) and presented with low back, groin and hip pain and difficulty in walking.
Patient's leukocyte count was $23.13 \mathrm{k} / \mathrm{mm}^{3}$ and CRP level was $227 \mathrm{mg} / \mathrm{L}$ at admission. It was considered as primary psoas abscess because there was no known additional disease (Figure 2). He operated under general surgery due to gastric perforation in the same session. MSSA had grown in the culture taken during the operation of the patient. He was admitted to general surgery service postoperatively and discharged from the general surgery department on the 8th postoperative day. In the postoperative follow-up, the patient's CRP level was $8.63 \mathrm{mg} / \mathrm{L}$ and WBC level was 7,49 $\mathrm{k} / \mathrm{mm}^{3}$.

\section{Case 4}

This patient was a male homeless (51 years)and presented with low back, groin and hip pain, high fever, nausea,vomiting and general condition disorder. Patient's leukocyte count was $13.28 \mathrm{k} / \mathrm{mm}^{3}$ and CRP level was $348 \mathrm{mg} / \mathrm{L}$ at admission. He had type II diabetes mellitus and Crohn's Disease as additional diseases. He had also flexion contracture of the hip and erythema of the skin (Figure 3). Percutaneous drainage was performed by interventional radiology to this patients and he was admitted to our service. Streptococcus agalactiae had grown in the culture taken during surgery. He was operated from different incisions (ilio-inguinal and lumbar) in two different sessions because of the failure to control the focus of infection and he was discharged with health after a total of 29 days of follow-up. In the postoperative follow-up, the patient's CRP level was $6.08 \mathrm{mg} / \mathrm{L}$ and WBC level was $6,41 \mathrm{k} / \mathrm{mm}^{3}$.

\section{Case 5}

This patients was a male worker (64 years). He presented with low back, groin and hip pain and difficulty in walking. As

Table 1. Demographic distribution of patients

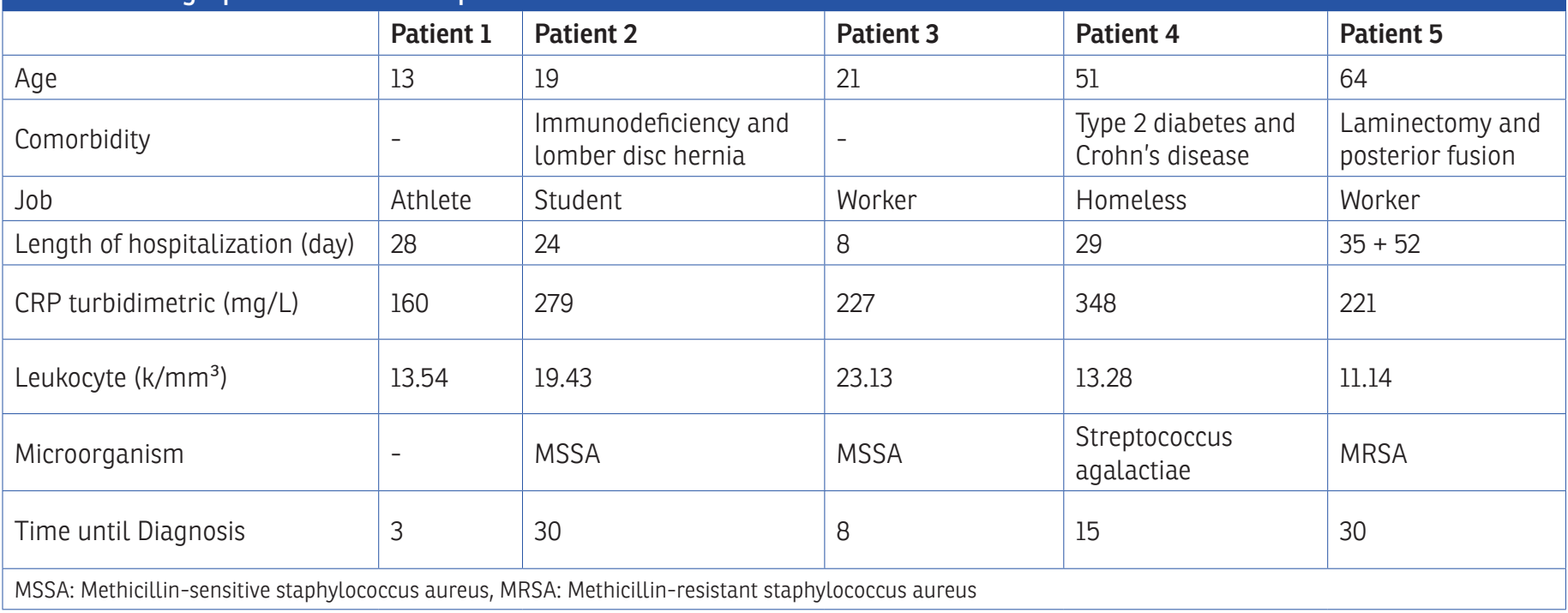


additional diseases he had L4-L5 laminectomy, discectomy and posterior instrumentation about 5 years ago. Other finding was diffuse edema in the lower extremity. Patient's leukocyte count was $11.14 \mathrm{k} / \mathrm{mm}^{3}$ and CRP level was 221 $\mathrm{mg} / \mathrm{L}$ at admission (Figure 4). Percutaneous drainage was performed by interventional radiology to this patient than admitted to our service. Methicillin-resistant staphylococcus aureus (MRSA) had grown in the culture taken during the operation of the patient. After psoas abscess was drained with open surgery in this patient, septic arthritis developed on the same side hip joint and the hip joint was debrided with open surgery (first hospitalization period 35 days). The patient recovered from the clinic and was discharged after 22 days of outpatient follow-up. In the third operation, antibiotic spacer was applied by femoral head resection and

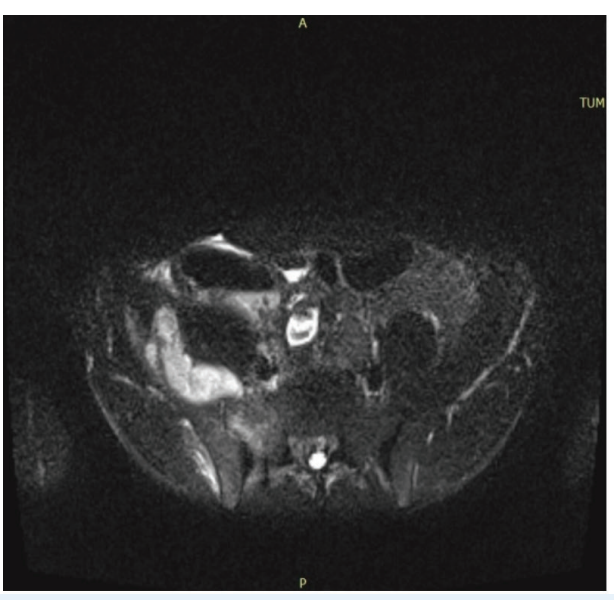

Figure 2. Twenty one years old male right psoas abscess (Case 3) axial preoperative MR images MR: Magnetic resonance

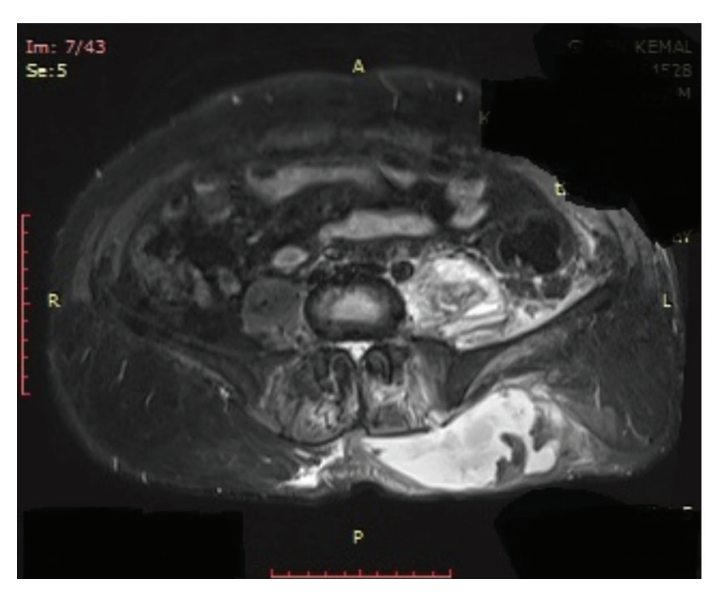

joint debridement. When the patient's clinical and laboratory findings improved during the follow-up, the patient had hip pain in his mobilization. The fourth operation was performed and the spacer was removed and the hip was left to girdlestone arthroplasty. The patient was discharged after the last operation (52 days). In the postoperative follow-up, the patient's CRP level was $3.40 \mathrm{mg} / \mathrm{L}$ and WBC level was $6.44 \mathrm{k} / \mathrm{mm}^{3}$.

\section{DISCUSSION}

Although psoas abscesses were diagnosed rarely, the incidence of these cases is reported higher in recent years due to the improvements in radiological imaging methods and the fact that these tests are used more frequently by clinicians ${ }^{(7)}$. We think that the Although in the literature it

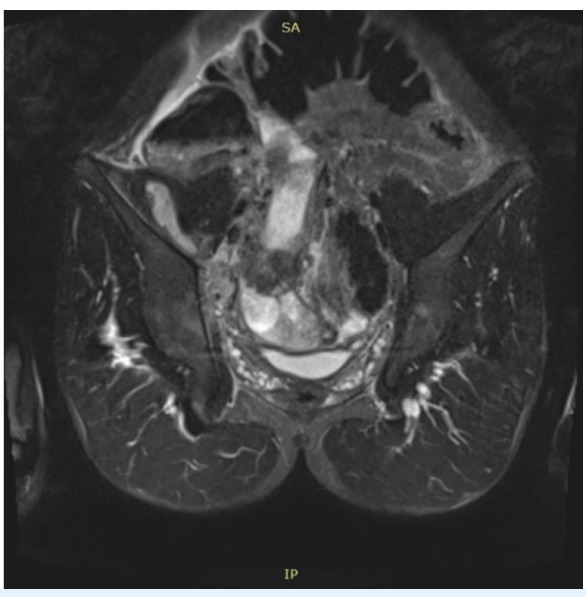

resonance

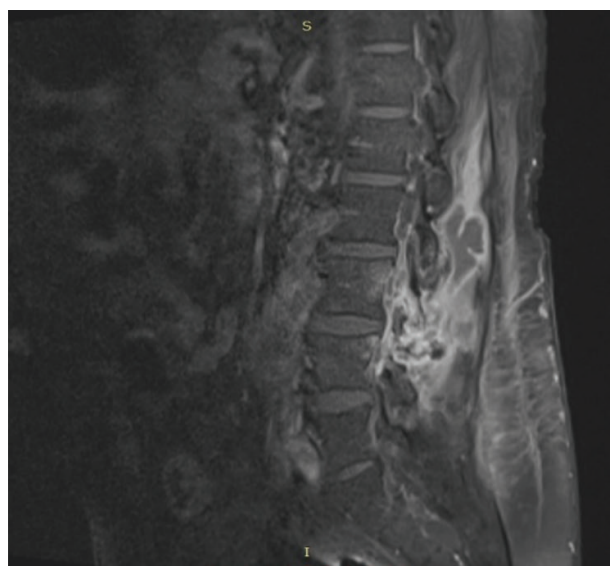

Figure 3. Fifty one years old male left psoas abscess (Case 4) axial and sagittal preoperative MR images MR: Magnetic resonance 

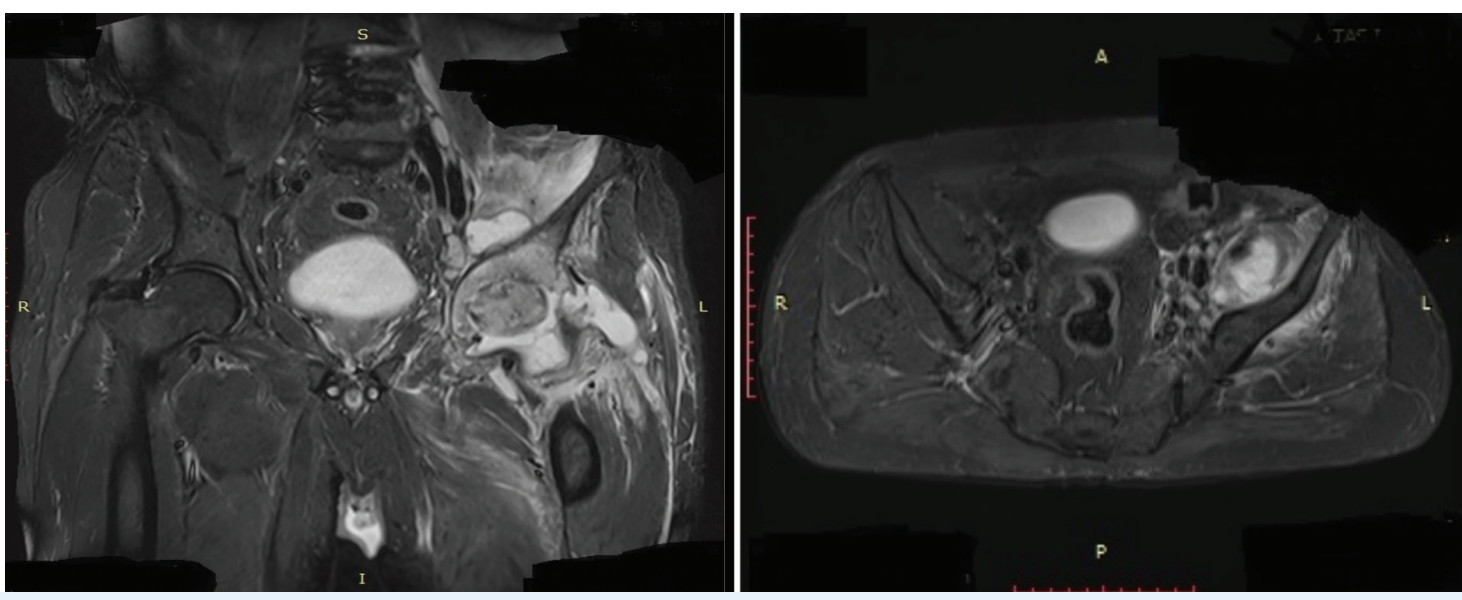

Figure 4. Sixty four years old male left psoas abscess (Case 5) coronal and axial preoperative MR images MR: Magnetic resonance

has been reported that $70 \%$ of psoas abcess patients are under the age of 20 , recent studies have identified the mean age above 40 years ${ }^{(7)}$. Also psoas abcess is seen more often in men ${ }^{(8)}$. In the present study all patients were men and mean age of patients was 33,6.

Side pain and fever are the most common symptoms in psoas abcess ${ }^{(9)}$. All of patients in the present study study had side pain and three of patients had high fever. In accordance with the literature, leukocytosis, high sedimentation rate and anemia were common laboratory findings in our patients.In the diagnosis of psoas abcess CT has a high sensitivity of up to $100 \%$. CT can show the location and depth of the lesion and also can show the exact sizes ${ }^{(10)}$. In this study CT was applied to all patients except 13-year-old patient. In order to show the soft tissue distribution of abscess after CT, MRI was applied to all patients.

Psoas abcess has been mostly reported unilaterally in the literature $(95-97 \%){ }^{(8)}$. All patients in the present study were also unilateral. Although right side involvement was reported in the literature, all but one patient were involved on the left side ${ }^{(8,11)}$.

Among all psoas abscesses, $30 \%$ is known as primary and $70 \%$ is as secondary abcess. The most common cause of primary psoas abscess is hematogenous spread, Crohn's disease is the most common cause of secondary psoas abscess (60\%) ${ }^{(12)}$. Other reasons are appendicitis (16\%), ulcerative colitis, diverticulitis, colon cancer ( $11 \%$ together) and vertebral osteomyelitis (10\%) in secondary psoas abcess ${ }^{(12)}$. In this study, $40 \%$ of patients had primary and $60 \%$ had secondary psoas abscess ${ }^{(7,8)}$. One of the patients with secondary psoas abscess in the study had
Crohn's disease, while the other two had spinal disease history.

The pathogen microorganism is staphylococcus aureus in $80 \%$ of primary psoas abscesses have been reported. Enteric bacteria are usually responsible for secondary psoas abscesses ${ }^{(13)}$. Staphylococcus aureus was found to be the causative agent in three patients in this study(one patient MRSA, two patients MSSA). In one of our patients, streptococcus agalactia was found as active microorganism, whereas in the other patient, no agent was produced in culture due to intensive antibiotic use.

Broad-spectrum antibiotics and drainage percutaneously or open surgery is the primary treatment of choice for psoas abcess ${ }^{(1,7,10)}$. Although percutaneous drainage is the primary treatment option today, it was first described in $1984{ }^{(14)}$. There are very few reports showing that only cases of psoas abcess respond to antibiotic treatment $(4,15)$. In general, open drainage with a more limited application is recommended when percutaneous drainage fails (8). Although percutaneous drainage is the most effective treatment, open drainage can achieve high success rates in worsened patients requiring fast and exact response. Percutaneous drainage was applied to $80 \%$ of patients, followed by open drainage in all patients in this study. Therefore, open drainage should be the first treatment of choice for these patients. Patients whose general health condition have deteriorated and delayed diagnosis were referred to our tertiary hospital. This may be the reason why open drainage is applied to all patients in our clinic.

Psoas abscess is a disease with fatal consequences. Mortality rate is $2,4 \%$ in primary psoas abscess and this rate may 
increase up to $18.9 \%$ in secondary psoas abscess ${ }^{(6)}$. In this study, one of the patients died and the exact cause of death of this patient could not be determined.

We think that early diagnosis, effective drainage and appropriate antibiotherapy are the key to manage this disease which is not easy to diagnose and treat. However, it should be kept in mind that serious complications, morbidity and mortality may occur in delayed cases.

\section{Ethics}

Informed Consent: Obtained.

Peer-review: Externally peer reviewed.

\section{Authorship Contributions}

Concept: C.Ö.H., H.B., C.E.Ü., A.A., C.E., Design: C.Ö.H., H.B., C.E.Ü., A.A., C.E., Data Collection or Processing: C.Ö.H., H.B., C.E.Ü., A.A., C.E., Analysis or Interpretation: C.Ö.H., H.B., C.E.Ü., A.A., C.E., Literature Search: C.Ö.H., H.B., C.E.Ü., A.A., C.E., Writing: C.Ö.H., H.B., C.E.Ü., A.A., C.E.

Conflict of Interest: No conflict of interest was declared by the authors.

Financial Disclosure: The authors declared that this study received no financial support.

\section{REFERENCES}

1. Gruenwald I, Abrahamson J, Cohen O. Psoas abscess: case report and review of the literature. J Urol. 1992;147:1624-6. doi: 10.1016/s00225347(17)37650-4.
2. Mynter H. Acute psoitis. Buffalo Med Surg J. 1881;21:202-10.

3. Ataus S, Alan C, Onder AU, Mihmanli I, Talat Z, Yalcin V. Psoas abscess. Cerrahpaşa J Med. 2003;31:89-93.

4. Mallick IH, Thoufeeq MH, Rajendran TP. Iliopsoas abscesses. Postgrad Med J. 2004;80:459-62. doi: 10.1136/pgmj.2003.017665.

5. Goldberg B, Hedges JR, Stewart DW. Psoas abscess. J Emerg Med. 1984;1:533-7.

6. Garner JP, Meiring PD, Ravi K, Gupta R. Psoas abscess-not as rare as we think? Colorectal Dis. 2007;9:269-74. doi: 10.1016/0736-4679(84)900076.

7. Bodakci MN, Hatipoglu NK, Daggulli $M$, et al. Etiological factors of psoas abscesses. J Clin Exp Invest. 2014;5:59-63. doi: 10.5799/ ahinjs.01.2014.01.0360

8. Tabrizian $\mathrm{P}$, Nguyen SQ, Greenstein A, Rajhbeeharrysingh U, Divino CM. Management and treatment of iliopsoas abscess. Arch Surg. 2009;144:946-9. doi: 10.1001/archsurg.2009.144.

9. Chern $\mathrm{CH}$, Hu SC, Kao WF, Tsai J, Yen D, Lee CH. Psoas abscess: making an early diagnosis in the ED. Am J Emerg Med. 1997;15:83-6. doi: 10.1016/s0735-6757(97)90057-7.

10. Turunç T, Demiroglu YZ, Colakoglu S. [Retrospective evaluation of 15 cases with psoas abscesses.] Mikrobiyol Bul. 2009;43:121-5. (Turkish)

11. Bresee JS, Edwards MS. Psoas abscess in children. Pediatric Infect Dis J. 1990;9:201-6. doi: 10.1097/00006454-199003000-00011.

12. Ricci MA, Rose FB, Meyer KK. Pyogenic psoas abscess: worldwide variations in etiology. World J Surg. 1986;10:834-43. doi: 10.1007/ BF01655254.

13. Santanella RO, Fishman EK, Lipsett PA. Primary versus secondary psoas abscess. Presentation microbiology and treatment. Arch Surg. 1995;130:1309-13. doi: 10.1001/archsurg.1995.01430120063009.

14. Mueller PR, Ferrucci JT, Wittenberg J, Simoene JF, Butch RJ. Iliopsoas abscess: Treatment by CT-guided percutaneous catheter drainage. AJR Am J Roentgenol. 1984;142:359-62. doi: 10.2214/ajr.142.2.359.

15. KadambariD, Jagdish S. Primary pyogenic psoas abscess in children. Pediatr Surg Int. 2000;46:408-10. doi: 10.1007/s003839900329. 